\title{
Musculoskeletal Teaching and Training in Saudi Internal Medicine Residency Programmes
}

\author{
Rania Zaini1 ${ }^{*}$, Hani Almoallim¹,2, Waleed Hafiz' ${ }^{2}$ Mayada Boyaan², Mohammad Samannodi1, \\ Alaa Al-Rehali', Suzan Awan', Haneen Hafith1, Dana Attar ${ }^{2}$ \\ ${ }^{1}$ Umm Alqura University, Makkah, Kingdom of Saudi Arabia \\ ${ }^{2}$ King Faisal Specialist Hospital and Research Centre (KFSHRC), Jeddah, Kingdom of Saudi Arabia \\ Email: *rgzaini@uqu.edu.sa
}

Received 24 February 2016; accepted 6 May 2016; published 9 May 2016

Copyright (C) 2016 by authors and Scientific Research Publishing Inc.

This work is licensed under the Creative Commons Attribution International License (CC BY). http://creativecommons.org/licenses/by/4.0/

(c) (i) Open Access

\begin{abstract}
Background: Musculoskeletal (MSK) conditions are among the most common complains presented at the clinical practice, accounting about $15 \%-30 \%$ of all primary care encounters. However, clinical doctors continue to document a low level of confidence in their musculoskeletal clinical skills. Objectives: The aim of this study is to evaluate the internal medicine (IM) residents for confidence and perception in demonstrating musculoskeletal clinical skills. Methods: 37 items paper-based questionnaire was developed and piloted to investigate IM residents in Saudi Arabia during June-December 2011. Results: The study indicates residents' low self-confidence in demonstrating MSK physical examinations with total mean $(10 / 24)$. Respondents also show general agreement that MSK problems are very common in patient visits, and indicate the importance of MSK clinical screening in all standard clinical examination of patients, yet they point to current inappropriate practice in handling most cases. Respondents show lower perception of undergraduate and postgraduate training, regarding the inadequate training and assessment in MSK. Conclusions: The study shows inadequate MSK education, during and post, medical school training and that there are different training approaches for the different specialties, which undermines MSK training altogether.
\end{abstract}

\section{Keywords}

Musculoskeletal, MSK, Saudi, Internal Medicine, Residency

\footnotetext{
${ }^{*}$ Corresponding author.
} 


\section{Background}

Musculoskeletal (MSK) conditions are among the most common complains presented at the clinical practice. It counts about 15\% - 30\% of all primary care encounters in the USA (Day and Yeh, 2008). Also it is considered the third major cause of outpatient visits at public hospitals, in Saudi Arabia (MOH, 2013). An MSK condition is also associated with significant health care expenditures and population morbidity. In a survey of eight countries, including Denmark, France, Germany, Italy, Japan, The Netherlands, Norway, and the United States, arthritis had the greatest negative impact on health-related quality of life (Alonso et al., 2004). MSK care is delivered by a spectrum of medical specialists, including internists, orthopedics and surgeons, pediatricians, family physicians, and general practitioners; yet they usually work with limited multispecialty focus.

Despite the high prevalence of MSK disorders in all fields of clinical practice, patients with MSK complaints are often ignored, and mostly their problems are overlooked. Studies report almost full documentation of cardiovascular, respiratory and gastrointestinal systems examinations but almost a major neglect of MSK examination (Akesson et al., 2003, Almoallim et al., 2007, Beattie et al., 2008, Almoallim et al., 2012). Such overlook of MSK examination and delay of diagnosis mostly lead to serious complications.

Studies reported limitations of the essential MSK competencies amongst medical trainees and physicians. A cross-sectional survey of two hundred and ninety-seven primary care indicated that MSK complains make up $30 \%-40 \%$ of daily practice. However about $80 \%$ of participants reported a low level of confidence in performing a musculoskeletal physical examination (Abou-Raya \& Abou-Raya, 2010). Other study indicated that 79\% of respondents including medical students, residents and staff physicians, failed the essential MSK cognitive examination (Matzkin et al., 2005). Investigators also reported overlooked of essential physical examination of MSK in residency education and undergraduate programmes (Freedman \& Bernstein, 1998, Day et al., 2007, Beran et al., 2012, Skelley et al., 2012, Comer et al., 2014).

A survey indicated that new medical graduates have lower competence in demonstrating physical examination especially for MSK and cardiovascular system (Ramani et al., 2010). In 2003, it was reported that about 50\% of the United State medical schools had no obligatory MSK basic sciences course or clinical clerkships (Di Caprio et al., 2003). Harvard medical students considered MSK medicine as the third most important topic in a physician's career, yet they presented low levels of confidence in MSK examination (Day et al., 2007). Medical school curricula represent scant attention for MSK medicine: It is estimated that only 3\% of most USA undergraduate curricular is devoted to MSK medicine (Craton \& Matheson, 1993). In Saudi Arabia, most medical curricula have (4-week block) in preclinical phase and 3-week rotation of Orthopedics surgery consisting 4\% - 5\% of curricula.

In 2005, the Association of American Medical Colleges highlighted the underrepresentation of MSK in medical curricula and recommended the essential competencies for medical graduates (AAMC, 2005). This concurred with the United States Bone and Joint Initiative announced Project 100, which recommended that $100 \%$ of US medical schools begin requiring a musculoskeletal course by the end of the decade. Accordingly, medical schools developed their MSK curriculum. However, most of these initiatives did not meet the expected results of improving medical students competencies of MSK (Wise et al., 2014, Day et al., 2011, Queally et al., 2009, Bilderback et al., 2008).

In the United Kingdom (UK), Nammari, et al (2009) highlighted that UK Foundation Programme currently provides inadequate training in MSK medicine. The MSK training exposure was limited; about $15 \%$ of the 112 respondents had any exposure to Orthopedics during the foundation programme and only $13 \%$ felt they had adequate exposure to MSK medicine (Al-Nammari et al., 2009). This concurred with Nigerian study that revealed inadequate musculoskeletal competency of the pre-internship Nigerian medical-school graduate, according the Freedman and Bernstein test for musculoskeletal competency (Nottidge et al., 2012).

In the postgraduate programmesthe same limitations have been emphasized since the 1980s: directors of residency programmesindicated that Rheumatology was not adequately covered such as cardiology or gastroenterology in Internal Medicine residency programmes (Goldenberg et al., 1985). General dissatisfactions of MSK training were reported in Internal Medicine residents and Family Medicine practice. United State residents expressed their dissatisfaction of their competence in performing MSK examinations at various parts of the body and reveal that to the inadequate or poor training (Clawson et al., 2001). Two hundred sixteen Internal Medicine residents, from 13 English language Canadian Internal Medicine programmes,reported poor self-confidence in Rheumatology diagnoses (5.24/10): They achieved considerably lower scores than all three comparator subspe- 
cialties, including cardiology, respiratory medicine, and gastroenterology (Katz \& Oswald, 2011). Another study reported Orthopedics residents' significant low score in the multiple-choice decision-making MSK patient examinations (Beran et al., 2012). Increasing year of training had no association with higher self-confidence for Rheumatology (Katz \& Oswald, 2011): neither it improved residents competence in MSK patients examinations (Beran et al., 2012). Many studies highlighted the essential need to review the residency training programmes.

\section{Objectives}

The main purpose of the study is to investigate the prospective of residents of Internal Medicine in Saudi Arabia of the importance of Musculoskeletal (MSK) medicine in daily practice, and determine their self-confidence to demonstrate MSK clinical skills in physical examinations.

The study highlights factors that affect the respondents' confidence, and explores educational and training opportunities provided in undergraduate and postgraduate programmes. It also attempts to determine the possible barriers that inhibit residents from developing essential competencies in MSK clinical skills.

\section{Methodology}

Paper-based, close-ended questionnaire with a 5-point-Likert scale is developed based on literature reviews. The questionnaire's first draft consisted of 42 items that focused on four major themes:

- Self-perception of competence in demonstrating MSK clinical skills.

- Current practice of MSK medicine in Saudi Arabia.

- Undergraduate education and postgraduate training in MSK medicine in general and MSK clinical skills in particular.

- Views of possible barriers toward adequate MSK clinical skills.

A pilot study with 3 respondents (intern-GP-consultant) was conducted during 15 - 22 May 2011. Respondents were asked to complete the questionnaire and identify possible negative aspects considering; instructions, ambiguous items, replicated items, and linguistic or stylistic issues. The questionnaire final draft consists of 37item along with demographic questions and a free comments part.

The study population is residents of the Internal Medicine (IM) in Saudi Arabia. The required sample size was calculated within confidence level of $95 \%$ and confidence interval of (5) for a population of seven hundred IM residents in the Kingdom by 2011. The required sample size was 248 respondents.

The option of electronic survey or questionnaire was suggested since the study is a national survey. However, the suggestion was not taken because research group believes that Saudi professionals will probably be not complete electronic survey so having the required response rate will be a challenge. Therefore, self-demonstration of a paper-based questionnaire is decided on considering, especially, that the questionnaire is a short one that will takes no more than five minutes to fill. Thereafter, programme coordinators in each region, city and teaching hospitals approached respondents. They were invited to participate in the study and were promised total confidentiality. The study was carried out from June-December2011.

The reliability of the survey was assessed using Cronbach's alpha. A scale with an alpha coefficient of 0.70 or more was considered acceptable reliability. All statistical analyses were done with SPSSIPC+V2.0.

\section{Ethical Considerations and Funding}

The protocol of the study was approved by King Faisal Specialist Hospital and Research Centre and funded by the AlZaidi Chair of Research in Rheumatic Disease, Umm AlQura University. An approval from Saudi Commission for Health Specialities and the directorate of IM Residency programmesis arranged before conducting the study.

\section{Results}

296 residents of Internal Medicine completed the questionnaire with 42\% response rate between June and December 2011. Respondents represent 21 residency programmes in ten different cities that covering five regions of the Saudi Arabia; Western Region 114 (39\%), Central Region 105 (35\%); Southern Region 39 (13\%), Eastern Region 27 (9\%) and Qassim 11 (4\%). The majority of respondents are male 185 (63\%), Saudi 246 (83\%), between 26 - 30 years old 210 (71\%), graduate from national medical schools $243(82 \%)$, and at their first or sec- 
ond year of the residency programme, 132 (45\%) and 77 (26\%) respectively.

The first aim of the study is to investigate respondents'self-perception of their competence in demonstrating essential MSK clinical skills. The study results indicate that residents have low confidence in demonstrating MSK physical examinations with a total mean of 10/24 (Table 1). Generally, respondents indicate their incompetent demonstration of different aspect of MSK physical examination, includes general MSK, hip and pelvis, elbow and wrist, foot and ankle, back, and kneephysical examinations.

The independent-sample t Test is applied and suggested statistical significant differences in the residents' perception of their confidence in demonstrating MSK physical examination according to their gender with $\mathrm{P} \leq$ 0.05. Male residents show higher confidence than female in demonstrating MSK physical examination especially of the hips and pelvis, and back. However, both groups showed moderate confidence in the physical examination of the knee, foot and ankle, and foot and ankle.

One-Way ANOVA is applied and suggested that there is no statistical significant differences in the residents' perception of their confidence in demonstrating MSK physical examination according to either respondents level at the residency programme or the site of training with $\mathrm{P}>0.05$.

The MSK practice of respondents is also investigated. Study results show a consensus among respondents about current practice: MSK problems are considered a common reason for a patient's visit to clinical practice. They indict the importance of MSK clinical screening in all standard clinical examination of patients; and also the inappropriate practice in handling most MSK cases. Respondents denote their inattention to perform MSK physical examination unless there is a serious complication, and their unfamiliarity of the GLAS locomotors screening procedures.

Undergraduate education and postgraduate training in MSK medicine in general and MSK clinical skills in particular are also investigated. Respondents exhibit low perceptions of their undergraduate and postgraduate training, regarding the inadequate training in MSK, the absence of mutual awareness between related teachers and departments about the MSK teaching approaches, and the assessed competence in MSK.

In addition, most residents agree that an integrated and consistent medical education and training of MSK physical examinations is essential to develop graduates and residents skills in the area. They also value the suggestion to increase curricular/rotation for MSK in medical schools and residency programmes

The developed survey was based on literature review and then reviewed by the research group. Then the survey was piloted to ensure its measure what supposed to measure. The alpha coefficient for the 37-item survey

Table 1. Residents self-confidence in demonstrating MSK physical examination according to gender.

\begin{tabular}{|c|c|c|c|c|c|c|c|}
\hline & Total mean & Gender & $\mathrm{N}$ & Mean & Std. Deviation & $\begin{array}{l}\text { Std. Error } \\
\text { Mean }\end{array}$ & Sig. (2-tailed) \\
\hline \multirow{2}{*}{ Phy Ex General } & 1.72 & Male & 183 & 1.8251 & .95620 & .07068 & .031 \\
\hline & & Female & 105 & 1.5810 & .85238 & .08318 & .026 \\
\hline \multirow{2}{*}{ *Phy Ex Hip/pelvis } & 1.35 & Male & 183 & 1.5027 & .95431 & .07054 & .000 \\
\hline & & Female & 105 & 1.0952 & .88278 & .08615 & .000 \\
\hline \multirow{2}{*}{ Phy Ex Elbow/wrist } & 1.85 & Male & 182 & 1.9835 & 1.02712 & .07614 & .015 \\
\hline & & Female & 105 & 1.6762 & 1.03306 & .10082 & .016 \\
\hline \multirow{2}{*}{ Phy Ex Foot/ankle } & 1.64 & Male & 182 & 1.7637 & 1.03753 & .07691 & .023 \\
\hline & & Female & 105 & 1.4667 & 1.09252 & .10662 & .025 \\
\hline \multirow{2}{*}{${ }^{*}$ Phy Ex Back } & 1.49 & Male & 183 & 1.6448 & 1.08413 & .08014 & .006 \\
\hline & & Female & 105 & 1.2857 & .98756 & .09638 & .005 \\
\hline \multirow{2}{*}{ Phy Ex Knee } & 2.04 & Male & 183 & 2.1202 & 1.08272 & .08004 & .229 \\
\hline & & Female & 105 & 1.9619 & 1.05542 & .10300 & .226 \\
\hline \multirow{2}{*}{${ }^{*}$ TOTAL mean } & $10.09 / 24$ & Male & 181 & 10.7956 & 5.30274 & .39415 & .006 \\
\hline & & Female & 105 & 9.0667 & 4.80638 & .46905 & .005 \\
\hline
\end{tabular}

\footnotetext{
${ }^{*}$ Significant differences with $\mathrm{P} \leq 0.05$.
} 
was 0.76 . The reliability of the 6-item scale, which measuring respondents' self-confidence in demonstrating MSK physical examination, was 0.92 . Thus, the study achieved acceptable reliability.

\section{Discussion}

The study aims to investigate the prospective of residents of Internal Medicine in Saudi Arabia of the importance of Musculoskeletal (MSK) medicine in daily practice and determine their self-confidence to demonstrate MSK clinical skills in physical examinations. The study shows a major threat in clinical practice in Saudi Arabia; that most Internal Medicine residents in the Saudi Arabia have low confidence in MSK physical examination. Most medical schools and Internal Medicine residency programmes do not effectively educate future physicians about MSK medicine in spite of the increasing prevalence of MSK conduction across medical practice. However, the respondents emphasise the importance of MSK medicine in daily practice. The study results concur with international surveys and studies about the low level of confidence in performing a MSK physical examination across medical students (Matzkin et al., 2005, Zaini et al., 2011, Ramani et al., 2010).

The study also points to the underestimation of prevalence of MSK conditions and to its impact on individuals and society in clinical and medical training programmes. MSK is not considered a main competency of medical graduates because it is not a life threatening conditions. The vague training of MSK in undergraduate and postgraduate programmesis obvious and it results in the fact that there is no significant improvement in residents' self-confidence in MSK examination regarding their year of study. This is also concurs with other international studies and reflects a worldwide concern (AAMC, 2005, Day et al., 2007, Clark et al., 2010, Beran et al., 2012).

Residents highlight the importance of systematic teaching and training and continuous education of MSK. Teachers and trainers role in developing such systematic training is essential. However it is not taking seriously as noted in Beran et al. study in their assessment of MSK physical examination skills and attitude of Orthopedic residents that both department chairs and residents agreed that, although learning to perform the physical examination is important, there is not enough time in the clinical setting to observe and critique a resident's patient examination (Beran et al., 2012). Teaching physical examination in graduate medical education programmesis a controversial; there is no single best strategy. Following the principles of deliberate practice and interaction with human examinees may be beneficial in teaching (Mookherjee et al., 2013). O’Dunn-Orto et al., reviewed the MSK's clinical skill teaching, and recommended engaging learners within meaningful interactive learning context and the effectiveness of patients as learning resources (O'Dunn-Orto et al., 2012).

Respondents also emphasis the lack of a standardized approach of clinical assessment of MSK problems whether presenting to primary care, Rheumatology or Orthopedics that give a benchmark for this competency. The clinical assessment of a musculoskeletal problem must be conducted following a standardized approach, as a benchmark for trainees'competency and can also be used in teaching and assessment

Nevertheless, there is a need to reconsider the undergraduate and postgraduate programmes, and the competencies of their graduates regarding MSK medicine. The study results develop a local intuitive supported by AlZaidi Chair of Research in Rheumatic Disease, Umm AlQura University toward better MSK clinical practice. A series of educational illustrative booklets for MSK Physical examination are designed and published, a series of continuous medical education workshops about MSK physical examinations are delivered in many hospitals in Makkah region. Holistic approach that considers the training curriculum, and continuous professional development is essential for better MSK clinical practice.

\section{Limitations of the Study}

MSK care is delivered by a spectrum of medical specialists, including internists, orthopedics and surgeons, pediatricians, family physicians, and general practitioners; yet this study focused only on the IM residents. National study with wider populations is recommended.

\section{Conclusion}

This study maps and investigates the problems of MSK education in Saudi Arabia despite the prevalence of the problem in Saudi society. It is found that there is no adequate, during and post, medical school training and that there are different training approaches for the different specialties, which undermines MSK training altogether.

The results confirm the discrepancy between the magnitude of MSK conditions and physicians competences. 
Therefore, an urgent national study is needed to focus on these problems to integrate the teaching and training, to create a teaching standardized approach, and to emphasize prompt MSK clinical screening in all standard clinical examination.

\section{References}

AAMC (2005). Report VII Contemporary Issues in Medicine: Musculoskeletal Medicine Education, Medical School Objectives Project No. VII, Washington DC: Association of American Medical Colleges.

Abou-Raya, A., \& Abou-Raya, S. (2010). The Inadequacies of Musculoskeletal Education. Clinical Rheumatology, 29, 1121-1126. http://dx.doi.org/10.1007/s10067-010-1527-y

Akesson, K., Dreinhöfer, K. E., \& Woolf, A. D. (2003). Improved Education in Musculoskeletal Conditions Is Necessary for All Doctors. Bulletin of the World Health Organization, 81, 677-683.

Al-Nammari, S. S., James, B. K., \& Ramachandran, M. (2009). The Inadequacy of Musculoskeletal Knowledge after Foundation Training in the United Kingdom. The Bone and Joint Journal, 19, 1413-1418.

Almoallim, H., Bukhari, E., Amasaib, W., \& Zaini, R. (2012). How to Avoid Delay in SLE Diagnosis and Management. In H. Almoallim (ed.), Systemic Lupus Erythematosus (pp. 219-242). Croatia: InTech. http://dx.doi.org/10.5772/26498

Almoallim, H., Khojah, E., Allehebi, R., \& Noorwali, A. (2007). Delayed Diagnosis of Systemic Lupus Erythematosus Due to Lack of Competency Skills in Musculoskeletal Examination. Clinical Rheumatology, 26, 131-133.

Alonso, J., Ferrer, M., Gandek, B., Ware, J. E., Jr., Aaronson, N. K., Mosconi, P., Rasmussen, N. K., Bullinger, M., Fukuhara, S., Kaasa, S., \& Leplege, A. (2004). Health-Related Quality of Life Associated with Chronic Conditions in Eight Countries: Results from the International Quality of Life Assessment (IQOLA) Project. Quality of Life Research, 13, 283-298. http://dx.doi.org/10.1023/B:QURE.0000018472.46236.05

Beattie, K. A., Bobba, R., Bayoumi, I., Chan1, D., Schabort, I., Boulos, P., Kean, W., Obeid, J., Mccallum, R., Ioannidis, G., Papaioanno, A., \& Cividino, A. (2008). Validation of the GALS Musculoskeletal Screening Exam for Use in Primary Care: A Pilot Study. BMC Musculoskeletal Disorders, 9, 115. http://dx.doi.org/10.1186/1471-2474-9-115

Beran, M. C., Awan, H., Rowley, D., Samora, J. B., Griesser, M. J., \& Bishop, J. Y. (2012). Assessment of Musculoskeletal Physical Examination Skills and Attitudes of Orthopaedic Residents. The Journal of Bone \& Joint Surgery, 94, e36. http://dx.doi.org/10.2106/JBJS.K.00518

Bilderback, K., Eggerstedt, J., Sadasivan, K. K., Seelig, L., Wolf, R., Barton, S., Mccall, R., Chesson, Jr., A. L., \& Marino, A. A. (2008). Design and Implementation of a System-Based Course in Musculoskeletal Medicine for Medical Students. The Journal of Bone \& Joint Surgery, 90, 2292-2300. http://dx.doi.org/10.2106/JBJS.G.01676

Clark, M. L., Hutchison, C. R., \& Lockyer, J. M. (2010). Musculoskeletal Education: A Curriculum Evaluation at One University. BMC Medical Education, 10, 93. http://dx.doi.org/10.1186/1472-6920-10-93

Clawson, D. K., Jackson, D. W., \& Ostergaard, D. J. (2001). It’s Past to Reform the Musculoskeletal Curriculum. Academic Medicine, 76, 709-710. http://dx.doi.org/10.1097/00001888-200107000-00012

Comer, G. C., Liang, E., \& Bishop, J. A. (2014). Lack of Proficiency in Musculoskeletal Medicine among Emergency Medicine Physicians. Journal of Orthopaedic Trauma, 28, e85-e87. http://dx.doi.org/10.1097/BOT.0b013e3182a66829

Craton, N., \& Matheson, G. O. (1993). Training and Clinical Competency in Musculoskeletal Medicine. Identifying the Problem. Sports Medicine, 15, 328-337. http://dx.doi.org/10.2165/00007256-199315050-00004

Day, C. S., Ahn, C. S., Yeh, A. C., \& Tabrizi, S. (2011). Early Assessment of a New Integrated Preclinical Musculoskeletal Curriculum at a Medical School. American Journal of Orthopedics, 40, 14-18.

Day, C. S., \& Yeh, A. C. (2008). Evidence of Educational Inadequacies in Region-Specific Musculoskeletal Medicine. Clinical Orthopaedics and Related Research, 466, 2542-2547. http://dx.doi.org/10.1007/s11999-008-0379-0

Day, C. S., Yeh, A. C., Franko, O., Ramirez, M., \& Krupat, E. (2007). Musculoskeletal Medicine: An Assessment of the Attitudes and Knowledge of Medical Students at Harvard Medical School. Academic Medicine, 82, 452-457. http://dx.doi.org/10.1007/s11999-008-0379-0

Di Caprio, M. R., Covey, A., \& Bernstein, J. (2003). Curricular Requirements for Musculoskeletal Medicine. The Journal of Bone and Joint Surgery. American Volume, 85, 565-567.

Freedman, K. B., \& Bernstein, J. (1998). The Adequacy of Medical School Education in Musculoskeletal Medicine. The Journal of Bone \& Joint Surgery, 80, 1421-1427.

Goldenberg, D. L., Dehoratius, J. K., Mason, J., Meenan, R., Perlman, S. G., \& Winfield, J. B. (1985). Rheumatology Training at Internal Medicine and Family Practice Residency Programs. Arthritis \& Rheumatism, 28, 471-476. http://dx.doi.org/10.1002/art.1780280420

Katz, S. J., \& Oswald, A. E. (2011). How Confident Are Internal Medicine Residents in Rheumatology versus Other Com- 
mon Internal Medicine Clinical Skills: An Issue of Training Time or Exposure? Clinical Rheumatology, 30, 1081-1093.

Matzkin, E., Smith, M. E. L., Freccero, C. D., \& Richardson, A. B. (2005). Adequacy of Education in Musculoskeletal Medicine. The Journal of Bone and Joint Surgery. American Volume, 87, 310-314.

MOH (2013). Health Statistics Annual Book: 2013. Riyadh: Riyadh General Directorate of Statistics \& Information, Ministry of Health.

Mookherjee, S., Pheatt, L., Ranji, S. R., \& Chou, C. L. (2013). Physical Examination Education in Graduate Medical Education-A Systematic Review of the Literature. Journal of General Internal Medicine, 28, 1090-1099. http://dx.doi.org/10.1007/s11606-013-2380-x

Nottidge, T. E., Ekrikpo, U., Ifesanya, A. O., Nnabuko, R. E., Dim, E. M., \& Udoinyang, C. I. (2012). Pre-Internship Nigerian Medical Graduates Lack Basic Musculoskeletal Competency. International Orthopaedics, 36, 853-856. http://dx.doi.org/10.1007/s00264-012-1485-x

O’Dunn-Orto, A., Hartling, L., Campbell, S., \& Oswald, A. E. (2012). Teaching Musculoskeletal Clinical Skills to Medical Trainees and Physicians: A Best Evidence in Medical Education Systematic Review of Strategies and Their Effectiveness: BEME Guide No. 18. Medical Teacher, 34, 93-102. http://dx.doi.org/10.3109/0142159X.2011.613961

Queally, J. M., Kiely, P. D., O’Daly, B. J., \& O’Byrne, J. M. (2009). Design and Implementation of a System-Based Course in Musculoskeletal Medicine for Medical Students. The Journal of Bone and Joint Surgery. American Volume, 91, 1276-1277.

Ramani, S., Ring, B. N., Lowe, R., \& Hunter, D. (2010). A Pilot Study Assessing Knowledge of Clinical Signs and Physical Examination Skills in Incoming Medicine Residents. Journal of Graduate Medical Education, 2, 232-235. http://dx.doi.org/10.4300/JGME-D-09-00107.1

Skelley, N. W., Tanaka, M. J., Skelley, L. M., \& Laporte, D. M. (2012). Medical Student Musculoskeletal Education: An Institutional Survey. The Journal of Bone and Joint Surgery. American Volume, 94, e146. http://dx.doi.org/10.2106/JBJS.K.01286

Wise, E. M., Walker, D. J., \& Coady, D. A. (2014). Musculoskeletal Education in General Practice: A Questionnaire Survey. Clinical Rheumatology, 33, 989-994. http://dx.doi.org/10.1007/s10067-013-2479-9

Zaini, R. G., Bin Abdulrahman, K. A., Al-Khotani, A. A., Al-Hayani, A. A., Al-Alwan, I. A., \& Jastaniah, S. D. (2011). Saudi Meds: A Competence Specification for Saudi Medical Graduates. Medical Teacher, 33, 582-284. http://dx.doi.org/10.3109/0142159X.2011.578180 